\title{
Polar Tourism: An Environmental Perspective
}

B. Stonehouse and J.M. Snyder. Channel View Publications, Bristol, 2010. viii + 217 pp. Price £29.95. ISBN 1-84541-145-5 (pbk).

Bernard Stonehouse and John Snyder are longstanding partners in polar tourism research. This is not the first contribution by these authors and I am sure it will not be the last. They have spent a lot of time at both ends of the earth, and this comes across in their new book. It is not long or complicated; it simply describes how things actually work in Arctic and Antarctic regions. They provide a valuable context for current tourism by outlining the history, patterns and trends in other human uses of these areas, from early exploration to modern research stations, military history to mining, and some of the politics of Indigenous habitation past and present.

The subtitle, however, is perhaps a little misleading. The book does outline various environmental management measures at broad scale. It does not, however, say much about the legal frameworks which apply in Arctic nations, nor the actual environmental practices of tour operators. Most importantly, it says remarkably little about the types and mechanisms of ecological impacts by tourists or other humans in polar regions. There is some excellent research, reviewed in Buckley (2004), on the impacts of tourists on penguins, other seabirds, seals, cetaceans, bears and other polar wildlife. This has examined changes in behaviour, heart rates, stomach temperature, stress hormones, predation and reproductive success. There are also reports of humans introducing weeds and pathogens into Arctic, Antarctic and sub-Antarctic ecosystems. The new book does not refer to any of this. Such an omission is especially surprising since Bernard Stonehouse himself wrote an illustrated book on Antarctic ecology nearly four decades ago (Stonehouse, 1972), of which I still have a copy. So, from an ecologist's view, this new volume is somewhat disappointing; but perhaps this is because it is written as part of a series on tourism.

This volume has nine chapters and six Appendices. The first three chapters provide a general introduction, and a review of the history and development of tourism in the Arctic and Antarctic respectively. Chapter 4 examines environmental and political change in the polar regions, and Chapter 5 reviews the particular challenges of 
tourism in polar wilderness areas. Chapter 6 examines shipborne tourism specifically, since this is the principal mode of tourist travel for most polar tourism. Chapter 7 covers culture and heritage, with a focus on modern day communities in the Arctic, and relics of early exploration in the Antarctic. Chapter 8 considers the sub Antarctic oceans and islands, which lie outside the Antarctic circle - whereas in the North, the island tourist destinations are within the Arctic Circle. Finally, Chapter 9 considers the future of polar tourism both as a set of commercial products, and as an industry subject to social and environmental management. The Appendices provide maps, lists of protected areas, summaries of relevant international conventions, and a set of minimal-impact guidelines produced by NGOs and tour operators. There are also illustrations and occasional text boxes throughout the main body of the book.

The text is generally terse and dense but still very readable, with bullet-point lists used to convey a large amount of information in a digestible way. There are relatively few references, and they are placed so as not to interrupt the sense or flow of sentences. The reference section, however, is certainly not a complete bibliography of tourism and environment in polar regions, and there is no index. Overall, this reads very much as an introductory overview, a basic primer on polar tourism. Perhaps it is intended to complement another volume by the same authors, Prospects for Polar Tourism, published by a competing publisher!

\section{References}

Buckley, R.C. (ed) 2004. Environmental Impacts of Ecotourism. CAB International, Wallingford. 389 pp.

Stonehouse, B. 1972. Animals of the Antarctic: The Ecology of the Far South. Holt, Rinehart \& Winston, New York. 171 pp

RALF BUCKLEY

International Centre for Ecotourism Research Griffith University, Australia E mail r.buckley@griffith.edu.au 